the determinants affecting adolescent psychological well-being. Methodology: In Mysore District, India, 319 adolescents 16-18 yr, were from urban and rural 11th and 12th grades. A structured questionnaire based on the "General Psychological well being scale" was used.

Results No significant difference in the scores of urban and rural adolescents $[\mathrm{v} 2=1.12, \mathrm{df}=3, \mathrm{p}>0.05]$. Economic backwardness positively correlates with the psychological stress in adolescents $[\mathrm{v} 2=9.15, \mathrm{df}=3, \mathrm{p}<0.05]$. In grade $2,64 \%$ reported difficulty in concentration compared to $10 \%$ in grade 5 . [ $\mathrm{v} 2=47.01, \mathrm{df}=2$, $p<0.001]$. There was no significant gender difference in the psychological score $[\mathrm{v} 2=1.44, \mathrm{df}=1, \mathrm{p}>0.05]$.

Conclusions Our study shows that there is no significant influence of urban and rural residence or gender on the psychological health of the adolescents. We conclude that the economic constraints on the adolescents were associated with lower psychological health. Lower psychological health is associated with decreased concentrating ability and thereby scholastic performance.

Recommendations The study also shows how a rapid screening technique can be incorporated into school health screening camps thereby enabling us to integrate mental health screening at an early stage into mainstream. The policies towards betterment of adolescent mental health should be directed towards their economic and academic needs than their areas of residence or gender.

\section{P2-532 A COMPARATIVE STUDY OF FREQUENCY OF POSTNATAL DEPRESSION AMONG SUBJECTS WITH NORMAL AND CESAEREAN DELIVERIES}

doi:10.1136/jech.2011.142976m.59

V Nagaraja,* M A Khan, G Bhat. Mysore Medical College and Research Institute, Mysore, Karnataka, India

Background Prevalence of postnatal depression (PND) is $12 \%-15 \%$. Recent studies are equivocal about the earlier inference that PND is higher among cesarean than normal delivery.

Objective The aim of this study is to investigate the frequency of PND among the Indian women and the association between the mode of delivery and PND.

Material and Method Fifty subjects each; having delivered normally and by cesarean section was chosen. All the women were within 3 months post delivery and could understand Kannada language. Those who consented were asked to complete the Edinburgh Postnatal Depression Scale (EPDS). Those found to have scores suggestive of depression on EPDS were assessed for depression according to ICD-10. The data were analysed using paired t test and $\chi^{2}$ test.

Conclusion Among Post caesarean subjects, depression was diagnosed in $20 \%(n=10)$ as compared to $16 \%$ in subjects that delivered normally. However there was no significant difference in the frequency of depression among the two groups. Due to the small sample size the results cannot be generalised.

\section{P2-533 AN EVALUATION OF THE FIRST GENDER-SPECIFIC SMOKING CESSATION COUNSELLING PROGRAM FOR FEMALE SMOKERS TO OUIT IN HONG KONG: A 3-YEAR FOLLOW-UP}

doi:10.1136/jech.2011.142976m.60

C S M Ng, ${ }^{*}$ D Y P Leung, Z Wan, I C Y Fu, T-H Lam, S S C Chan. The University of Hong Kong, Hong Kong, Hong Kong

Introduction Woman smoking is a complicated addiction, and they always find smoking cessation difficult. A nurse-led gender-specific smoking cessation counselling program was initiated to address these problems in Hong Kong. This study aims to test the efficacy of the program at a 3-year follow-up.

Methods A gender-specific smoking cessation programme has been set up for female smokers in 2006. Women smokers aged 15 years or above and smoked in the past month were recruited to receive 3sessions of individualised face-to-face stage-matched smoking cessation counselling at baseline, 1-week, and 1-month. They were followed up at 6 month, 1 year, and 3 years to assess their smoking status. We reported the quit rate and compared changes in their cigarette consumption from baseline to 3 year.

Results From November 2006 to November 2010, we received over 800 inquires and provided smoking cessation counselling to 386 eligible female smokers. A total of 174 participants were eligible for follow-up at 3 years, and $130(74.7 \%)$ were successfully contacted. Participants aged 36 years (range: 15-74), had smoked for 18.2 years $(\mathrm{SD}=8.9)$ with a mean daily consumption of 15.4 cigarettes $(\mathrm{SD}=8.8)$. Using intention-to-treat analysis, the selfreported 7-day point prevalence quit rate was $11.4 \%$ (44/386). Among those continued to smoke $(n=84)$, the cigarette consumption reduced from $16.0 \pm 9.4$ to $11.9 \pm 8.0(\mathrm{p}<0.001)$ on average; and $29.8 \%(n=25)$ had reduced cigarette consumption by at least half.

Conclusion The gender-specific cessation programme seemed to be effective in promoting smoking cessation and reduction among Chinese female smokers in Hong Kong.

\section{P2-534 CULTURAL PRACTICES AND BELIEFS OF PENIS ENLARGEMENT AND IMPLANT IN PAPUA, INDONESIA}

doi:10.1136/jech.2011.142976m.61

${ }^{1}$ A Oktavian, ${ }^{* 2,3}$ W Diarsvitri, ${ }^{3}$ I Dwisetyani. ${ }^{1}$ National Institute of Health Research and Development for Biomedicine, Papua Province, Indonesia, Jayapura, Indonesia; ${ }^{2}$ Department of Community Health, Faculty of Medicine, Hang Tuah University, Surabaya, Indonesia; ${ }^{3}$ Australian Demographic and Social Research Institute, The Australian National University, Canberra, Australia

Papua Province has the highest prevalence of HIV/AIDS in Indonesia and in 2009, 94.4\% cases were transmitted through heterosexual intercourse. High risk sexual behaviours, including multiple sex partners, early initiation of sexual activity, penis enlargement and implant, have been widely practiced among Papuan men. These practices have been passed from generation to generation through sexual culture and beliefs without understanding the health consequences that it might cause. The uses of "wrapping leaves", such as Dendrocnide stimulans and Eurycoma longifolia, dried leech oil, tree sap or silicon injection, as well as implanting a metal or plastic subcutaneously to enhance the erect phallus are commonly found among Papuan men. The aim of this study was to explore various types of penis enlargement and implant, the extent and the reasons of the practice, health consequences and treatment seeking behaviour. We used qualitative method, including in-depth interview among men, their partners, medical and non-medical profession, as well as observation. The first author is a medical doctor stationed in Jayapura and has been documenting cases of penis enlargement and implant in his clinic.

Results Indicated that the practice is carried out in unhygienic condition. The practice was usually started in teenage years either by traditional healer, with a help from a friend or self. Almost all men who had penis enlargement or implant visited the doctor when they experienced severe inflammation, infection, penile tissue damage or other medical complication that hindered their reproductive function and made them more susceptible to HIV/AIDS and other STD infection. 